\title{
ANÁLISE ETNOBOTÂNICA DA ESTRUTURA DE QUINTAIS NA FRONTEIRA BRASIL/PARAGUAI
}

\author{
ENTNOBOTANICAL ANAL YSIS OF FARM STRUTURE IN BRAZIL/PARAGUAY \\ BORDER
}

\author{
${ }^{1}$ Sebastião Gabriel Chaves Maia e ${ }^{2}$ Sederli Bombarda Sobrinho
}

${ }^{1,2}$ Faculdades Magsul - Av. Presidente Vargas, 725, Centro, Ponta Porã-MS, CEP: 79.904-616. E-mail: sgchavesmaia@gmail.com; sederli@hotmail.com

\section{RESUMO}

Submitted: 20/07/2019; Accepted: 05/10/2019

O presente estudo foi realizado no núcleo urbano do município de Ponta Porã-MS, tendo como foco a estrutura do quintal, constituindo uma importante fonte de informações etnobotânicas, bem como as características socioculturais que constituem a população fronteiriça. As informações etnobotânicas foram obtidas por meio de observação participante e entrevista semiestruturada realizadas em 30 unidades domésticas devidamente acompanhadas de seus mantenedores. Os resultados obtidos foram constituídos com base nas informações qualiquantitativas, levando em consideração a forma de organização dos espaços, as espécies vegetais cultivadas nos quintais e as formas de usos, segundo a percepção dos moradores. No estudo foram identificadas 200 etnoespécies pertencentes a 65 famílias botânicas agrupadas em quatro estratos distintos: herbáceas, subarbustos, arbustos e arbóreas. Com tudo, observou-se que esses espaços além de serem considerados por muitos como extensão da residência são utilizados para finalidades distintas como: cultivos de diferentes categorias de plantas ornamentais, medicinais, alimentícias, criação de pequenos animais, lazer e de uso místico. Vale ressaltar ainda, a função social que os quintais desempenham promovendo a interação desses atores sociais, contribuindo na manutenção das relações socioculturais estabelecidas entre essa população, na conservação e, principalmente na transmissão desses conhecimentos ao longo das gerações.

Palavras-chave: unidades domésticas; conhecimento etnobotânico; conhecimentos tradicionais.

\begin{abstract}
The present study was conducted in the urban nucleus of Ponta Porã-MS, focusing on the backyard structure, constituting an important source of ethnobotanical information, as well as the sociocultural characteristics that constitute the border population. Ethnobotanical information was obtained through participant observation and semi-structured interviews conducted in 30 domestic units duly accompanied by their maintainers. The obtained results were constituted based on the qualitative and quantitative information, taking into consideration the form of organization of the spaces, the vegetal species cultivated in the backyards and the forms of uses, according to the residents perception. In the study we identified 200 ethnospecies belonging to 65 botanical families grouped in four distinct strata: herbaceous, sub-shrubs, shrubs and trees. However, it was observed that these spaces, besides being considered by many as an extension of residence, are used for different purposes such as: cultivation of different categories of ornamental, medicinal, food, small animal breeding, leisure and mystical use. It is also worth mentioning the social function that the backyards play promoting the interaction of these social actors, contributing to the maintenance of the socio-cultural relations established between this population, conservation and, especially, the transmission of this knowledge over the generations.
\end{abstract}

Keywords: domestic units; ethnobotanical knowledge; traditional knowledge.

\section{INTRODUÇÃO}

A etnobotânica é uma ciência interdisciplinar integrada às diferentes áreas das etnociências, que se dedica em estudar os fenômenos relacionados ao conhecimento popular de diferentes culturas, bem como, seu modo vida e sua interação com os recursos naturais, especialmente com as plantas. De acordo com Begossi (1993), a etnobotânica insere-se no domínio mais amplo da etnobiologia, que compreende o estudo do conhecimento e das conceituações desenvolvidas por qualquer sociedade sobre os seres vivos e os fenômenos biológicos. 
O conhecimento que a população tem sobre os recursos vegetais, mesmo que de forma geral, possibilitaram que o ser humano ao longo da sua história desenvolvesse diferentes estratégias de exploração e manutenção e, consequentemente, o uso dos recursos naturais necessários a sua própria existência em diversas formas, como a domesticação de espécies vegetais para diferentes finalidades, construção de abrigo, alimentação, vestimentas, combustível, artesanatos, tratamentos de enfermidades, uso místico, entre outras.

Algumas dessas importantes formas de domesticação estão representadas nos quintais, que segundo Maia (2016), é uma das formas mais antigas de manejo por serem espaços de fácil acesso e cômodo e que possuem longa tradição em países tropicais.

Neste sentido, o quintal doméstico, como definido por Posey (1987), é o espaço geralmente localizado ao redor da residência, onde são cultivadas plantas consideradas úteis e decorativas.

Além das finalidades já mencionadas, podemos destacar ainda, a importância biológica representada pelos componentes encontrados, considerados verdadeiros patrimônio genético e refúgio de espécies exóticas, ameaçadas de extinção conforme constatado em outros estudos, mencionado por Amorozo (2008), a qual afirma que em regiões economicamente desenvolvidas e com predomínio de monoculturas, os quintais podem ser o último reduto desta agrobiodiversidade. Tal questão é vivenciada na região de Ponta Porã-MS.

Com base nessas informações, o presente estudo tem por objetivo geral conhecer a estrutura etnobotânica dos quintais urbanos do município de Ponta Porã MS.

A escassez de trabalhos abordando as questões etnobotânicas em nossa região serviu como mola propulsora para o desenvolvimento do estudo com o objetivo de realizar um estudo etnobotânico em quintais urbanos do município de Ponta Porã - MS, bem como, compreender as interações existentes entre os moradores e o espaço que circunda a residência.

Estudos dessa natureza inserem-se um uma área ainda carente de informações e pouco explorada em nosso Estado e, principalmente no que se refere à região de Fronteira Brasil/Paraguai, por considerar que esses diferentes grupos sociais que aqui coabitam apresentam formas diferenciadas de manusear, identificar, classificar, conceituar e fazer uso desses recursos.

Essa particularidade vivenciada em nossa região representa uma importante fonte de informações etnobotânica e etnoecológica, que segundo Noda (2000) é utilizada para investigar o conhecimento a respeito do uso que uma população faz dos recursos naturais existentes.

Estudos como este na região são relevantes devido às características específicas que constituem a população fronteiriça, delimitado por uma única rua e seus moradores circulam constantemente nesses espaços, contribuindo no fortalecimento dos laços socioculturais, que constitui uma população com múltipla culturalidade e características singulares, na qual, tal questão é pouco explorada pelo meio científico.

Além disso, eles podem apontar diferentes alternativas para potencializar o uso de espaços (mesmo que reduzido) no cultivo de produtos de subsistência. Diversos estudos nessa área têm demonstrado a contribuição dos quintais na segurança alimentar, tratamento de enfermidades, uso místico, criação de pequenos animais, dentre outros. Albuquerque (2005) enfatiza a relevância de estudos como este, colocando que as plantas sempre foram importantes nas atividades sociais e religiosas, na agricultura e na mitologia de qualquer sociedade.

Vale ressaltar ainda que a disseminação desses conhecimentos contribui para que mais pessoas possam se apropriar desses benefícios incorporando-os em seu modo de vida, apontar novas potencialidades econômicas a serem exploradas como forma de promoção da melhoria da complementação da dieta alimentar, melhoria no microclima local, proporcionando qualidade de vida e bem-estar da população fronteiriça.

Podemos ressaltar ainda que a população pontaporanense apresenta forte influência da cultura paraguaia. Esta característica pode ser associada a dois fatores evidenciados na região: as relações comerciais estabelecidas entre os moradores e o elevado número de indivíduos paraguaios que estabeleceram residência no Brasil, incorporando ao seu modo de vida hábitos e costumes típicos do país vizinho.

Neste contexto, a literatura estudada demonstra que os estudos nessa área de fronteira constituem importantes ferramentas de compreensão sobre as diversas formas de apropriação, manejo e uso dos recursos com finalidades distintas como: alimentar, medicinal, ornamentação, atividades relacionas ao lazer, por representar um espaço de socialização e convivência dessas populações, o que de certa forma, contribui para a manutenção das relações sociais, culturais e tradicionais locais. 


\section{QUINTAL COMO ÁREA DE INTERAÇÃO HOMEM-AMBIENTE}

O quintal, como o principal foco deste estudo, pode revelar características socioculturais específicas do grupo estudado, tanto na sua forma de organização, quanto nas práticas de manejo e as diferentes finalidades para as quais as plantas são destinadas, levando em consideração as influências socioculturais vivenciadas e adquiridas ao longo do tempo.

Como sugere Carniello (2008), além das influências amplas, os quintais também refletem influências mais circunscritas e imediatas, determinadas tanto pela trajetória de vida da família, como pelas características pessoais, necessidades e interesses do proprietário.

Sobre essa perspectiva, os quintais representam uma rica fonte de informações etnobotânicas, sendo uma importante reserva de plantas alimentícias, medicinais, ornamentais e para outros diversos fins.

Neste sentido, o quintal é muito mais que uma mera porção de terreno, é um espaço social e cultural, no qual as famílias mantêm uma grande diversidade de plantas, fazendo uso delas de forma sustentável e garantindo assim a sua conservação. Carniello (2008) também compartilha com essa definição afirmando que os quintais são destinados para finalidades distintas como aclimatar, sombrear, ornamentar, prevenir e curar enfermidades, alimentação da família e uso místico.

Além das funções já mencionadas, destacamos também as contribuições relacionadas à estética do quintal através do cultivo de plantas ornamentais, muitas vezes obtidas pela troca de mudas e sementes entre vizinhos e familiares constituindo um espaço de agradável climatização, proporcionando bem-estar e qualidade de vida aos moradores.

Como nos revela Guarim Neto e Fracaro (2008, p. 76) é no quintal, sob a sombra proporcionada pelas árvores, que se encontram mesas, bancos de madeira, o fogão-a-lenha e o tanque de lavar roupas. É neste local, que as pessoas se reúnem e os costumes são transmitidos ao longo das gerações. Complementando isso, Amorozo (2002), nos diz que os quintais contribuem para manutenção de relações de vizinhanças e parentesco na medida em que fornecem elementos (plantas medicinais, frutas, hortaliças, mudas plantas etc.) que circulam pela rede social juntamente com informações sobre seus empregos e significados, contribuindo tanto para manter vivas as tradições locais como para disseminar germoplasma de interesse para a população.

\section{PROCEDIMENTOS METODOLÓGICOS}

O presente estudo foi realizado no município de Ponta Porã, Mato Grosso do Sul, localizada na região Sul do Estado. De acordo com senso do IBGE (2010), o município tem cerca 83.000 habitantes. Sua economia está pautada na agricultura e pecuária e também é conhecida como Princesinha dos Ervais.

Faz divisa seca com Pedro Juan Caballero, província de Amambay, Paraguai, um importante polo comercial, sendo visitado por pessoas de várias regiões de país. Essas interações econômicas fortalecem os laços sociais e culturais dessa população e possibilita a troca de experiências e saberes, que são resguardados e repassados através de gerações.

A metodologia que norteou o presente trabalho segue os pressupostos da pesquisa etnobotânica e etnoecológica, considerando o quintal como foco do estudo, com intuito de compreender a organização social do grupo estudado, bem como, as relações estabelecidas entre a sociedade e os recursos naturais disponíveis, através da verificação de sua compreensão sobre etnoespécies potencialmente úteis a população, bem como as práticas de manejo desses espaços.

A presente pesquisa teve como base um estudo qualiquantitativo, estruturado em um estudo de caso. Segundo Baruffi (2002), as informações qualitativas, dada as suas peculiaridades dos fenômenos relacionados à natureza, tornou-se o método científico capaz de descobrir as relações existentes entre diferentes fenômenos, ao buscar suas causas e explicar seus efeitos e o significado que as pessoas dão às coisas e a sua vida é foco de atenção especial do pesquisador.

Maia (2011) complementa essas afirmações e considera que, no mundo dos significados, das relações humanas com o meio, no geral, nos estudos de fenômenos, os dados quantitativos e as informações qualitativas se complementam.

As estratégias de coleta e tratamento dos dados adotados no presente estudo seguem os métodos propostos por Martin (1995), e também as orientações teórica e práticas discutidas por Amorozo (1996), Ming (1996) e Albuquerque (2002).

A coleta de dados teve a duração de 04 meses, de junho a setembro de 2016. Para a coleta de dados foram estabelecidas três fases de contato com a comunidade que compreendeu: 
1) delimitação da área de estudo envolvendo os bairros contemplados no sorteio abrangendo todo o núcleo urbano do Município de Ponta Porã-MS;

2) observação exploratória para diagnóstico dos domicílios que apresentam espécies vegetais manejadas e consideradas úteis pelo respectivo responsável e que se dispuseram a participar do estudo.

Nesta fase foram realizadas as entrevistas que de acordo com Marconi (2003, p. 195) são um encontro entre duas pessoas, a fim de que uma delas obtenha informações a respeito de determinado assunto, orientadas por um roteiro semiestruturado com perguntas abertas e fechadas.

Para Albuquerque e colaboradores (2012), o roteiro de entrevista semiestruturado, é a melhor opção no qual as perguntas são parcialmente elaboradas pelo pesquisador antes de ir a campo, caracterizando o perfil do informante quanto aos aspectos culturais, socioeconômicos e a forma pela qual os recursos naturais são assimilados.

3) em seguida o domicílio foi caracterizado quanto a sua extensão através da elaboração do croqui da propriedade, período de fundação, número de habitantes da casa, composição florística, manejo adotado no cultivo de plantas, formas de uso e o processamento para obtenção dos produtos advindos dos recursos vegetais do quintal.

Os quintais amostrados foram definidos por meio de sorteio eletrônico ${ }^{1}$. Para o sorteio considerou-se um total de 58 bairros, agrupados de acordo com o período de fundação. Para isso, foram estabelecidos três intervalos de tempo, sendo que 18 deles surgiram entre 1950 a 1965, 11 bairros entre 1966 a 1980 e 18 bairros entre 1981 a 1995.

Deste total, 30 deles foram selecionados através do sorteio abrangendo todo o núcleo urbano do município. Assim a escolha das unidades domésticas se deu de forma aleatória, sendo que em cada bairro, foram realizadas duas entrevistas, uma em cada quadra.

As entrevistas foram realizadas com o responsável pelo domicílio, sendo homens e mulheres acima de dezoito (18) anos de idade. Na coleta de dados foi adotada a observação participante de acordo com o que dispõem Lüdke e André (1986) e Amorozo (1996). A última autora sintetiza as proposições dos autores mencionados afirmando que a observação participante é um método tradicionalmente usado em antropologia, que consiste na apreensão, por meio de uma interação cotidiana entre o pesquisador e os membros da comunidade estudada, da forma como opera a cultura em questão e como os atores sociais veem o seu mundo. As técnicas de observação participante perpassaram por todas as atividades desenvolvidas durante o período de coleta e análise dos dados nos quintais amostrados.

A observação participante que de acordo com Guarim Neto (1994, p. 132 e 133), ela acontece através do contato direto do pesquisador com os fenômenos observados. O objetivo desta técnica é obter maiores informações sobre a realidade do local. Becker (1993) citado por Neto (2008), também enfatiza essa afirmação colocando que o observador-participante coleta os dados por meio da participação no cotidiano do grupo estudado. Essa aproximação contribui para a compreensão das conceituações, interpretações e situações que são observadas. Segundo Guarim Neto (2008), uma vez que o pesquisador se torna conhecido, isso facilita o acesso e a confiabilidade dos entrevistados.

Assim, como técnicas de pesquisa o presente trabalho utilizou o Termo de Consentimento Livre e Esclarecido; respeitando os aspectos éticos inerentes à pesquisa etnobotânica. Conforme determinações da Resolução 466/12 para pesquisas que envolva seres humanos. No qual está explicita os objetivos do estudo, devendo ser apresentadas a cada um dos participantes, sendo esses convidados a participar do estudo.

Entrevista semiestruturada através da elaboração de um questionário com questões abertas e fechadas, que possibilitou ao entrevistador aprofundar os questionamentos, quando julgou necessário. Utilizou ainda o registro fotográfico, que foram fundamentais para identificar as etnoespécies encontradas de acordo com o sistema de etnotaxonomia (sistema de classificação ou nomeação popular) que foram apresentadas durante a entrevista.

O caderno de campo foi uma ferramenta indispensável durante a pesquisa, a fim de registrar informações relevantes para o estudo. Neste, ficaram registradas as emoções, sentimentos e percepções dos entrevistados em relações ao espaço que circunda a casa e tudo que o compõe e as percepções pesquisador com as situações vivenciadas em campo.

Foi realizada a turnê-guiada, elemento essencial na identificação das etnoespécies, pois realizar a turnê nos quintais acompanhada do entrevistado (a) é fundamental para validar os nomes das plantas citadas durante a entrevista, (pois o nome pode variar bastante de entre os entrevistados).

\footnotetext{
${ }^{1} \mathrm{O}$ referido sorteio eletrônico utilizou a plataforma do site sorteador.com
} 
A identificação foi realizada por meio de pistas taxonômicas: para identificação foram consideradas as pistas taxonômicas descritas pelo entrevistado, armazenadas, através do registro fotográfico nomeado de acordo com que ele identifica a etnoespécie.

Para o perfil socioeconômico considerou-se as variáveis como sexo, idade, grau de instrução, ocupação, renda familiar, a fim de avaliar se isso implica em diferentes padrões de conhecimento e caracterização da estrutura presente nos quintais.

Os dados foram analisados qualitativamente e tiveram como base a análise de conteúdo proposta por Bardin (1997), que consiste em um conjunto de técnicas de análise das comunicações que acredita no rigor do método como forma de não se perder na heterogeneidade do objeto.

A coleta e a análise dos dados aconteceram de forma simultânea, na qual as notas de campo foram organizadas em conjuntos fisicamente separados, dos quais os mais importantes são: lembretes, notas campo e diário de campo. Ambos os casos, as páginas e a notas foram identificadas em ordem numérica, sendo atribuído um número para cada entrevistado, seguido da data e local da entrevista. $\mathrm{O}$ mesmo autor afirma que a importância da codificação é que reduz a informação complexa a um conjunto relativamente pequeno de ideias e torna possível encontrar padrões em grande quantidade de dados qualitativos.

A fisionomia dos quintais foi descrita com base em Millat e Mustafa (1998), por um diagrama de perfil, realizado com base em dois componentes: vertical e horizontal, de acordo com a localização das espécies. A estrutura vertical foi traçada com base nas medidas de diâmetro ao nível do solo - DNS e altura das possíveis espécies lenhosas da área. A estrutura horizontal da vegetação foi avaliada por meio da localização das espécies dentro do quintal, através da elaboração do croqui de cada unidade.

O critério para definição de árvore segue os conceitos utilizados por Guedes-Bruni (2002), no qual estão inclusos os fetos arborescentes e palmeiras. Além do uso das técnicas descritas acima, na coleta de campo buscou-se registrar todas as espécies vegetais existente no quintal, conforme delimitação descrita pelo morador.

Os quintais também foram classificados de acordo com o tipo de organização da fisionomia vegetal encontrada: jardim vertical e/ou horizontal; horta vertical e/ou horizontal; culturas caseiras (pequenas roças) e outras tipologias. Essas informações foram relacionadas com a distribuição dos vegetais no quintal.

\section{RESULTADOS E DISCUSSÃO \\ Caracterização da população estudada}

A população estudada é constituída em sua maioria por sul-mato-grossenses, sendo que Ponta Porã representou o município de maior influência na constituição da população, com $51,72 \%$ (n=15) dos entrevistados. Os demais são oriundos de cidades vizinhas, como Aral Moreira, com dois (02) representantes e Naviraí com um (01) representante. Enquanto que 13,79\% (n=4) dos indivíduos são oriundos de outros estados como: Paraíba, Rio de Janeiro, Rio Grande do Sul, Paraná e Santa Catarina. Além desses, há ainda uma (01) pessoa de nacionalidade Paraguaia e, com visto de permanência no país.

Vale ressaltar que esses imigrantes, ao fixarem residência neste município trouxeram consigo as influências socioculturais advindas dos grupos sociais adjacentes refletidas na estruturação e na composição florística existente nos quintais.

Dentre os informantes, $80 \%$ são mulheres $(n=24)$ e $20 \%$ homens $(n=06)$. Essa maior representatividade do sexo feminino deve-se ao fato da mulher dedicar-se mais tempo às atividades domésticas, incluindo as tarefas relacionadas ao manejo com quintal.

Resultados semelhantes já haviam sido encontrados em outros trabalhos como de Amorozo (2002); Florentino e colaboradores (2007); Freitas e colaboradores (2012); Moura e Andrade (2007), nos quais as mulheres representaram a maior parcela dos entrevistados. Fato este, evidenciado durante as visitas, durante as quais elas demonstravam afinidade quanto ao plantio, manejo e o uso dos recursos vegetais existentes nos quintais.

O intervalo de idade entre os entrevistados variou entre 18 e 78 anos, sendo que $34,6 \%$ ( $n=09$ ) estão na faixa etária de 18 e 28,34,6\%(n=09) entre 33 a 58 anos e 61 á 78(n=08), ou seja, 30,76\%, resultabdo em uma média de 44,5 anos. Faixa etária semelhante a essa foi encontrada por Florentino et al. (2007) em Caruaru-PE; Carniello e colaboradores (2010), em Mirassol do Oeste-MT; Freitas e colaboradores (2012) em São Miguel-RN.

Quase todos os entrevistados $(\mathrm{n}=29)$ dos classificaram como zona urbana do município de Ponta Porã, o local onde está instalada a sua residência. Destes 97\% (n=29) se declararam como sendo 
de nacionalidade brasileira e um deles se identificou como sendo paraguaio, mas que já vive no Brasil há bastante tempo.

O número de membros na família abrange um intervalo de (01) a sete (07) dentre as unidades visitadas, uma média de 3,2 indivíduos por residência. Desse total, 55,17\% $(\mathrm{n}=14)$ das unidades visitas residem duas a três pessoas e $44,82 \%$ com número mais expressivo de quatro a sete moradores, adultos e crianças.

Sobre a ocupação, aposentados e desempregados somaram $20 \%$ (06) integrantes, todos os demais possuem pelo menos uma atividade remunerada, na qual $44,8 \%$ dos entrevistados declaram ter renda mínima de um (01) salário mínimo.

\section{Caracterização dos quintais urbanos}

Cuidar dos espaços denominados quintais requer um entendimento inicial que esses espaços possuem delimitações diferenciadas no contexto da comunidade humana que está sendo observado (GUARIM NETO, 2008).

Dessa forma, os quintais constituem espaços de íntimas interações com o proprietário, que ao longo de tempo vai sendo moldado, desenhado de acordo com aspectos e experiências vivenciadas ao longo da vida de seus proprietários.

No entanto, esta forma de compreensão requer do pesquisador um olhar sensível e holístico do contexto que o envolve, aliado a uma postura desprovida de preceitos e opiniões consolidadas a respeito do universo estudado, tornando-se elemento fundamental para compreender a cultura local praticada.

Sob essa perspectiva, podemos inferir que a população analisada apresenta formas particulares de identificar e ordenar, ou até mesmo referir se as questões relacionadas ao quintal, principalmente no que se referem à definição, significados e importância de determinadas regiões que compõem a unidade doméstica.

Ainda sobre os quintais Guarim Neto (2008 p.197), nos mostra que estes são espaços de conservação e manutenção dos aspectos mais peculiares que uma população pode traduzir em seu cotidiano.

Uma abordagem etnoecológica é dada por Guarim Neto e Carniello (2004), ao discutirem os pressupostos biológicos e culturais, fazendo um paralelo entre os recursos vegetais e a cultura da população humana, com intuito de revelar o quanto ela pode ser diversificada.

No que se refere às relações estabelecidas entre a sociedade humana e as plantas presente nos quintais, Nair (1986) citada por Florentino e colaboradores (2007), observam que a composição florística e a distribuição das espécies nos quintais são determinadas por fatores externos e internos, como função, tamanho, área do quintal, bem como fatores socioeconômicos e culturais; e a influência direta da família que seleciona as espécies de acordo com as suas necessidades.

\section{As diversas tipologias encontradas}

A distinção das áreas que compõem o domicílio é definida pelos proprietários de acordo com a finalidade, as quais o espaço está destinado, sendo o de maior representatividade os setores denominados como: jardim, quintal, pátio, frente da casa, fundos dentre outros. As tipologias apresentam na pesquisa estão ilustradas na Figura 1.

O jardim, geralmente ocupa a região anterior ao domicílio, destinados prioritariamente ao cultivo de plantas ornamentais, medicinal, condimentares e algumas frutíferas de pequeno porte como, por exemplo, a acerola (Malpighia glaba L.), Ovaia (Eugenia blstantha Cambess.), entre outras.

No entanto, a regiões posteriores as residências (denominada fundo da casa pelos entrevistados), são cultivadas as espécies arbóreas de maior porte como: mangueiras (Mangifera indica L.) abacate (Persea americana Mill), mexerica (Citrus reticulata Blanco), jabuticaba (Plinia cauliflora (Mart) O) entre outras, que além de fornecerem os frutos utilizados na alimentação do núcleo familiar, fornecem sombra, um recurso muito utilizado pelos moradores pelos moradores para o melhoramento do microclima e na prática cultural muito comum na região, o hábito de tomar tereré sobre a sombra de uma árvore, acompanhados de amigos e familiares.

Outra definição de representou importância significativa citada por $15 \%$ dos entrevistados, refere-se à garagem como sendo um espaço de múltiplas finalidades, dentre ela o cultivo de epífitas como: samambaias, orquídeas, trepadeiras entre outras, de pequeno porte, geralmente cultivada em 
vasos suspensos com função de ornamentação dos espaços. A definição de casa foi dada por $14 \%$ dos entrevistados como sendo o espaço de refúgio, aconchego, descanso e tranquilidade.

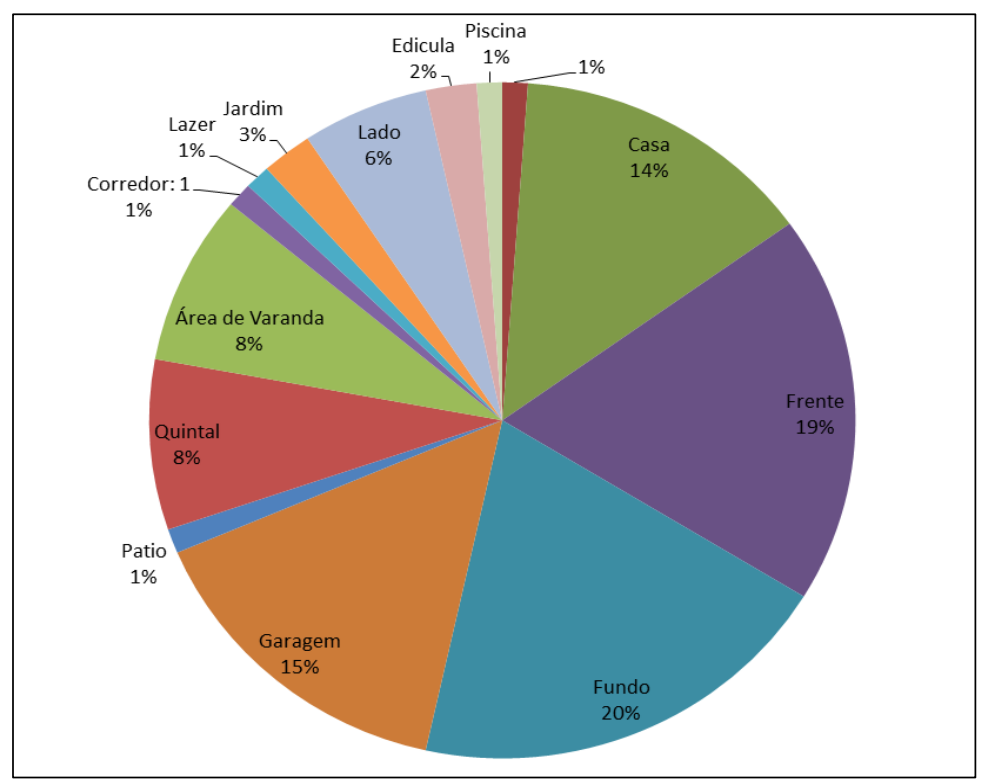

Figura 1: Definição dos espaços/tipologias que compõem os quintais.

De acordo com a concepção dos moradores a definição de quintal está diretamente relacionada ao espaço no qual são desenvolvidas as atividades relacionadas ao lazer da família, sendo o local reservado onde as crianças brincarem, praticarem diversas atividades, também é usado para o cultivo de vegetais obtidos através da troca de mudas, sementes e até mesmo parte do que é produzidos é trocado entre os moradores, evidenciando a contribuição dos quintais para que as relações de vizinhança e parentesco se concretizem.

Características como esta foram registradas durante a entrevista e transcrita abaixo. Segundo Conceição (70 anos), o hábito de cultivar plantas é extremamente prazeroso:

[... esse é o espaço da casa que mais gosto, passo muito mais tempo aqui do que dentro de casa, tudo que tenho aqui, ganhei das minhas amigas e sempre que posso repasso as mudas para aqueles que não têm, além de repartir o que sobra da produção...].

As demais tipologias ilustradas na Figura 7 foram citadas como forma de identificar determinados locais dentro do limite da residência, mas que não apresentaram uma importância significativa quando comparadas às demais.

\section{Finalidades para quais os vegetais são cultivados}

Quanto à finalidade dos vegetais cultivados nos quintais representam um universo de informações etnobotânicas que são construídas através de experiências e situações vivenciadas ao longo de suas vidas que poderão proporcionar inúmeras possibilidades de explorar os recursos disponíveis.

Levou-se em consideração as etnoespécies citadas pelos moradores, bem como a percepção quanto ao uso e a finalidade dos recursos. Dentre eles podemos destacar: alimentícias, ornamentais, medicinais, místico e sombra. Conforme descrito a seguir, de acordo com a ordem de importância em que elas foram citadas durante o estudo:

Alimentícias, os vegetais que apresentam potencial alimentício representam a primeira ordem de importância para os entrevistados, sendo considerado pelo proprietário como item prioritário na implantação das espécies que apresentam o cultivo das espécies com propriedades alimentares representaram destinadas prioritariamente a complementação na dieta alimentar do núcleo familiar, onde os produtos como frutas, verduras e legumes são consumidos em natura ou através de cozimentos.

O excedente da produção é processado na própria residência através de preparo de geleias, compotas, vitaminas ou ainda no preparo de suco natural obtido da extração de sua polpa. 
Dessa maneira podemos considerar que a produção oriunda dos quintais constitui uma importante fonte diária de vitaminas e minerais, conforme recomendados pela Organização Mundial da Saúde (OMS).

Uso medicinal, o número expressivo de etnoespécies encontradas nos quintais demonstra o recorrente uso deste recurso praticado pela população entrevistada. O cultivo de plantas com propriedades terapêuticas foram apontadas pelos entrevistados como sendo uma alternativa imediata no tratamento ou alívio de sintomas agudo anteposto ao tratamento médico.

Ornamental, as espécies vegetais que apresentam aspectos atrativos como a cor, flor, perfume ou até mesmo aspectos morfológicos da planta como as folhas, caules, raízes, etc.. Aparecem na totalidade das unidades domésticas visitadas, com origens distintas e com objetivo de alegrar, embelezar, tornar o espaço atrativo e assim contribuir para o bem-estar social.

Uso místico, os vegetais atribuídos a essas finalidades são consideradas pelos moradores como plantas "protetoras" que são utilizadas para proteger a família contra mau-olhado, benzimentos, amuleto de sorte dentre outros.

Nesta categoria está inclusa, a arruda, a guiné, comigo-ninguém-pode e a jurema-da-sorte. Este resultado está em conformidade com Pasa (2007 p. 72), sobre as comunidades do Bambá em Cuiabá MT, identificando plantas cultivadas com objetivo de oferecer proteção pessoal a seus moradores. Sobre o cultivo da planta identificada como jurema-da-sorte, conforme descrito pela moradora, de 68 anos.

[...] essa é a jurema-da-sorte, na minha família todos tem essa planta dessa em casa. Ela traz sorte e dinheiro, quando a gente planta coloca uma moeda no fundo do pote, assim nunca falta dinheiro em casa. Além disso, ela sofre junto com a gente, quando você adoece e também fica feia. Pode olha, esses dias fiquei internada é por isso que ela está com essa cor amarelada nas folhas. Mas agora que melhorei ela também vai ficar bonita logo-logo.

A simbologia associada a este vegetal já havia sido descrita por Mota (2002, p.15):

[...] a jurema é, portanto, mais que uma planta: é uma representação, divindade, mulher e vinho. Assim sendo, todo um conjunto de crenças se lhe encontra associado. As plantas denominadas jurema ocupam, com efeito, um papel destacado na flora nordestina pela referência mágico-religiosa [...] A jurema penetrou na cultura popular estando associada à figura de índios, caboclos e mestres, elementos presentes no imaginário popular [...].

Já o uso da guiné (Petiveria alliacea L.) é usado pra múltiplas finalidades como benzimento. No ritual, as folhas (geralmente três folhas), são usadas para curar incômodos como cortar cobreiros, benzer crianças de susto, dor de dente, quebrante, e outras doenças do corpo. Além disso, ele também é indicado para mau-olhado e más energias que rodeiam a casa.

Nessas residências elas estão inseridas junto ao jardim, localizado geralmente na região anterior a residência. Com objetivo de proteger seus moradores das energias negativas e assim evitar futuros males.

Essas manifestações demonstram as crenças e as simbologias estão inseridas de modo intrínseco a cultura que integra o contexto sociocultural da população estudada.

Sombreamento: nesta categoria prevalece às espécies com grande quantidade de folhas como, por exemplo, a mangueira (Mangifera indica L.). Essa categoria aparece como sendo uma das prioridades dos moradores na estruturação do espaço, como alternativa para amenizar os efeitos excessivos do calor, além de contribuições relacionadas à umidade, temperatura e solo através da produção de matéria orgânica.

As regiões dos quintais que possuem sombreamento foram citadas por 56,6\% ( $\mathrm{n}=17)$ dos entrevistados como sendo o espaço destinado às atividades relacionadas ao lazer de adultos e crianças, descanso, tranquilidade, convívio, socialização e interação com os vizinhos, amigos e parentes representando, portanto, o espaço na qual a cultura da população pontaporanense se expressa através de seu cotidiano.

No entanto, elas não representam o valor mais expressivo, considerando que os resultados representados seguem a ordem em que as finalidades foram citadas durante a entrevista (ordem de importância). 
Conforme pode ser observado na figura 2, as etnocategorias foram agrupadas seguindo a ordem descrita pelos moradores.

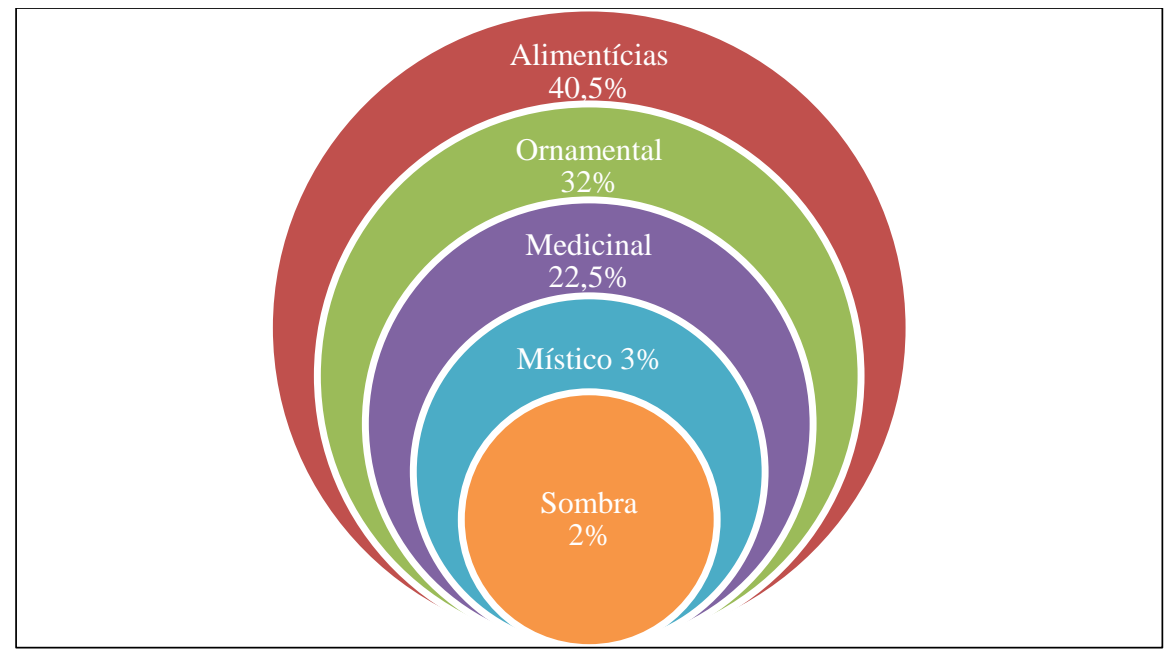

Figura 2: Finalidade dos vegetais cultivados nos quintais urbanos do Município de Ponta Porã-MS. As finalidades foram classificadas seguindo a ordem com as informações registradas durante a entrevista.

Os resultados apresentados na figura seguem a ordem de primeira importância mencionada pelos informantes que apesar das regiões sombreadas aparecerem em 56,6\% dos quintais visitas, essas finalidades não foram citadas pelos entrevistados como sendo prioritária, assumindo posição subsequente na ordem de importância.

Em relação aos cuidados com o quintal as mulheres aparecem em 55,7\% dos domicílios como sendo a principal responsável pelo plantio, manejo e manutenção das espécies. Dessa forma, elas representam força de trabalho na unidade familiar, pois além das atividades produtivas, ainda é responsável pelas tarefas domiciliares, conforme pode ser observado na figura 3.

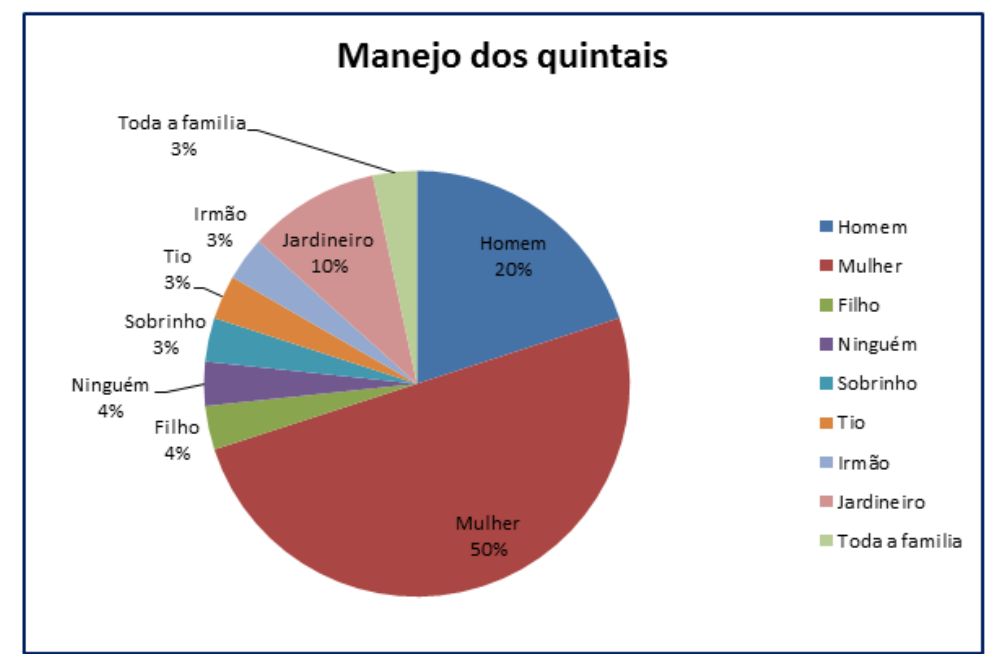

Figura 3: Quem desenvolve as atividades relacionadas ao cuida do quintal

O mesmo resultado foi encontrado Vieira (2006), em estudo realizado em quintais de Benevides e Igarapé-açú no estado do Paraná, onde as mulheres são as principais responsáveis pela implantação e manejo dos quintais. Guarim Neto e colaboradores (2002) em seu estudo constataram que em $60 \%$ das propriedades analisadas a tarefa de cultivar e manejar o quintal são atribuídos às donas de casa.

Ainda em relação ao manejo dos quintais, Constantin (2005), nos traz que ele também pode ser feito por indivíduos ligados por laços de parentesco, com um alto grau de conhecimento do ambiente onde vivem.

A alto percentual de participação da mulher no manejo do quintal evidencia o importante papel desempenhado pela mulher na conservação da biodiversidade de espécies, no gerenciamento dos 
recursos considerados de fácil acesso e na disseminação das espécies, fato este atribuído por elas como reflexo do que aprenderam sobre a alimentação, ornamentação e a medicina praticada com seus antepassados.

Esse tipo de transmissão do conhecimento, em relação a vegetais já haviam sido registrados em outros estudos (OLIVEIRA e colaboradores 2010; BRITO e BRITO, 1996; LEV e AMAR, 2000).

Destacamos aqui o carinho e o afeto demonstrados pelos informantes durante o passeio pelo quintal ao referir-se as plantas como: "filha", "minha vida", "é tudo que tenho", "são minha maior riqueza". Depoimentos que evidenciaram esse afeto, como este registrado durante a entrevista e transcrito abaixo:

[...] acordo cedo, e, a primeira coisa que faço é dar bom dia, elas gostam de atenção e carinho. [...] se eu pudesse ficaria o dia todo no quintal, só cuidando das minhas plantinhas. Peço mudas, quando encontro uma planta diferente porque gosto de ter no quintal, além de deixar bonito elas ajudam a refrescar no calor (PARTICIPANTE 1).

No entanto, foi possível perceber alguns padrões que vão sendo estabelecidos naturalmente ao longo da convivência com a unidade física, em relação:

a) a forma de organização do espaço;

b) as espécies cultivadas e a finalidade para a qual e destinada, (embora tenha sido imputadas diferentes funções para a planta, existem tendências que se assemelham entre si) e;

c) as práticas de manejo adotadas por seus empreendedores.

A forma de organização do espaço apresentou algumas variações em relação às divisões do espaço que compõem a unidade doméstica, no que se refere à posição em que está estabelecida a residência.

De acordo com os entrevistados, há uma preocupação em relação ao aproveitamento do espaço físico de forma que a casa seja geralmente construída em uma das laterais do terreno, com exceção de dois (02) quintais, essa estratégia tem por objetivo reservar áreas maiores, tanto na porção anterior quanto a posterior da residência, onde são cultivadas as espécies ornamentais, medicinais e algumas espécies arbóreas, ficando evidente a valorização desses recursos pelos moradores no melhoramento estético do espaço e bem estar da família.

Sobre essas observações Amorozo (2002), diz que as fisionomias dos quitais são moldadas por uma combinação e variações de sua estrutura, função e tamanho. Já em relação ao conteúdo e a finalidade dos recursos são estabelecidos de acordo com a história de vida das famílias que ocupam esse espaço, por tanto, refletem as experiências adquiridas pelos membros da família ao longo da vida.

Com tudo foi possível perceber que não há um padrão estabelecido em relação à metragem dos terrenos, apresentando por tanto, tamanho variados. Sendo que o menor deles possui $220 \mathrm{~m}^{2}$, os demais apresentaram tamanhos variados entre $300 \mathrm{~m}^{2} a ̀ ~ 1.100 \mathrm{~m}^{2}$, constituindo uma estrutura complexa e multiestratificada, com tamanho suficiente para atender a demanda familiar, constituído por elevado número de espécies.

O tempo de residência nos quintais variou entre dois (02) meses a sessenta (60) anos, não havendo relações consideráveis entre o tempo de existência e tamanho da área com a diversidade encontrada.

Observou-se apenas que há um sistema de seleção das espécies em relação ao tamanho dos quintais, com uma tendência de se cultivar as espécies de hábito ecológico que vai das herbáceas até arbustos (no máximo 1,5 m de altura), em quintais com áreas reduzidas, ou ainda, em quintais a qual a área construída ocupa a maior parte do terreno.

Há única uniformidade apresentada e está relacionada à representação geométrica, em que $100 \%$ dos quintais visitados são retangulares. A localização das espécies dentro quintais tem como referência a unidade doméstica, sendo que as espécies ornamentais estão geralmente localizadas na região anterior a residência, evidenciado o interesse do proprietário em relação à estética da moradia, $o$ mesmo resultado foi encontrado por Albuquerque (2006 p. 43).

Esses resultados foram evidenciados com maior intensidade em quintais próximos da área central do núcleo urbano, nas quais as espécies ornamentais chegaram a representar $100 \%$ dos vegetais cultivados, enquanto que em bairros mais afastados observam-se uma tendência em priorizar espécies com potencial alimentício e medicinal, em detrimento das ornamentais. 
Tal situação foi constatada por Lemonte e colaboradores (1999 citado por Albuquerque, 2006), na qual a presença de espécies ornamentais está associada a proximidade do centro urbano, porém há um significado cultural e estético na sua seleção.

Neste contexto, os fatores socioeconômicos e culturais representaram interferências significativas na composição florística que compõem os quintais amostrados, constatando que em quintais de famílias cuja renda familiar ultrapassa os três (03) salários mínimos, foi possível observar uma incidência maior de espécies ornamentais cuja finalidade se restringe a função estética do espaço, adquiridas através de compras em feiras e comércio local.

Nos bairros mais afastados, onde o poder aquisitivo das famílias tende a ser mais escasso, observou-se maior diversidade de espécies, riqueza e abundância, em relação aos quintais implantados na área "nobre" da cidade, pois de acordo com Fonse-Kruel e Peixoto (2004), os recursos da biodiversidade são fatores fundamentais para o desenvolvimento econômico, social e cultural das sociedades humanas.

Outro fator que devemos observar aqui está relacionado à interação e envolvimento desses indivíduos com o quintal em relação aos cuidados, uso, e conhecimento sobre os recursos cultivados e a finalidade para a qual e destinada.

Neste contexto, foi possível observar uma íntima interação com o quintal em indivíduos de idade avançada e economicamente menos favorecidos, que na maioria dos casos tem em suas origens o meio rural. Trouxeram consigo o hábito de cultivar, colher e fazer o uso desses recursos apresentando pleno domínio no cultivo e manejo dos vegetais que são utilizados por estes, como matéria-prima na produção de bens e serviços em benefício da própria família e da comunidade ao seu redor.

Nos demais bairros os moradores alegaram não dispor do tempo necessário em relação ao cuidado dos mesmos, devido às atividades realizadas fora da residência, sendo que nestes casos os cuidados são realizados por terceiros ou pelo próprio dono nos pequenos intervalos de tempo como finais de semana e feriados.

Abaixo estão retratados três (03) quintais com características semelhantes aos demais em sua estrutura e composição florística. A fim de retratar de forma simbólica o perfil horizontal e vertical dos quintais estudados.

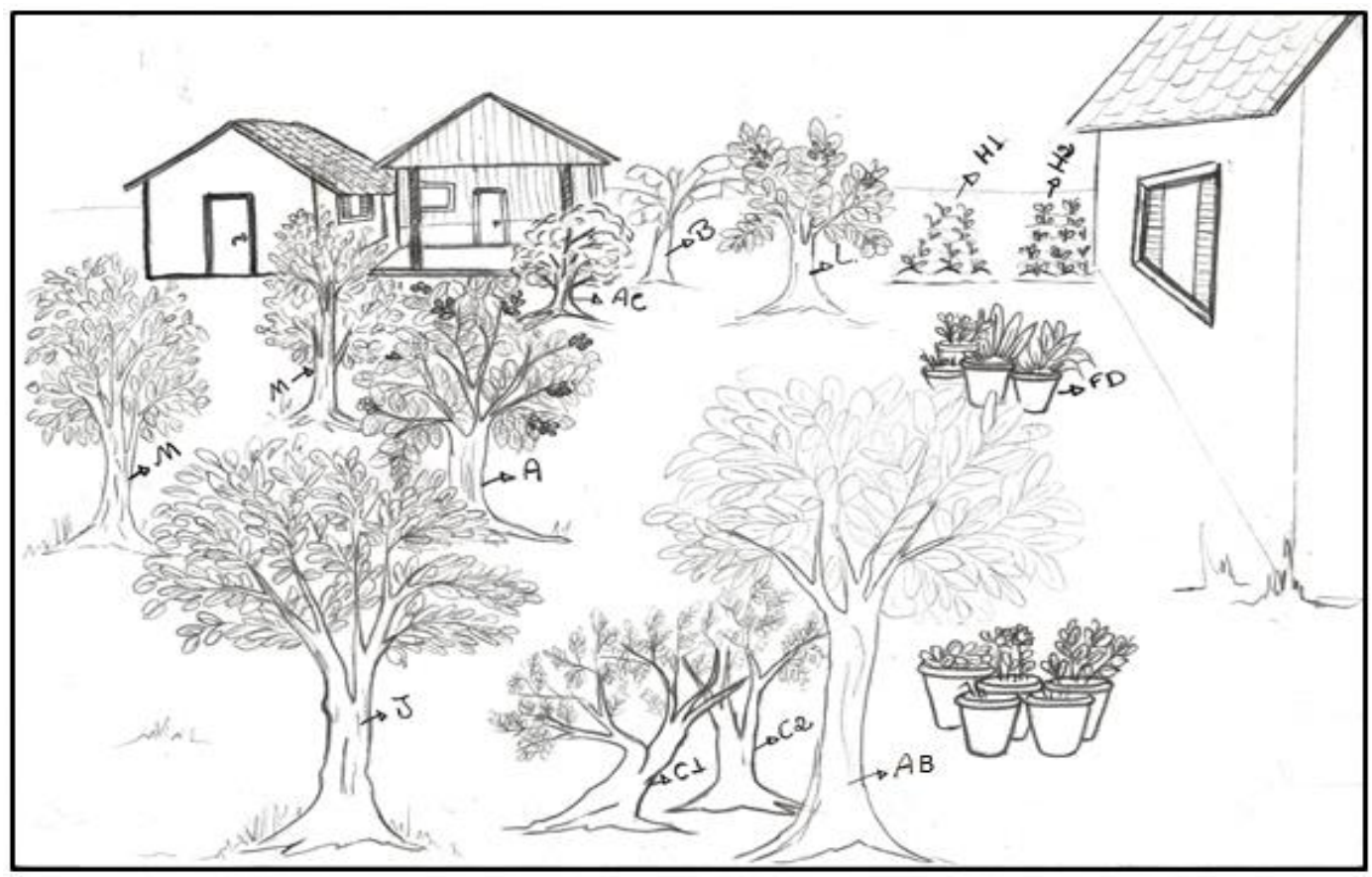

Figura 4: Croqui $\mathrm{n}^{\circ} 01$ representou 3,44\% dos bairros. Neste primeiro exemplo a casa está posicionada na região posterior do terreno. Na imagem é possível observar a estrutura a horizontal e vertical do quintal amostrado 
Tabela 1: informações etnobotânicas das espécies arbóreas ilustradas na figura 4.

\begin{tabular}{ccccc}
\hline Identificação & Nome popular & Nome científico & Diâmetro (cm) & Altura aproximada (m) \\
\hline $\mathrm{A}$ & Ameixa & $\begin{array}{c}\text { Eriobotrya japônica } \text { Rodr.et } \\
\text { Choussy }\end{array}$ & 15 & 3 \\
\hline $\mathrm{B}$ & Banana & Musa paradisíaca L. & 15 & 2,5 \\
\hline $\mathrm{C} 1$ & Siriguela & $\begin{array}{c}\text { Spondias purpúrea } \\
\text { L. }\end{array}$ & 25 & 2,5 \\
\hline $\mathrm{C} 2$ & Siriguela & $\begin{array}{c}\text { Spondias purpúrea } \\
\text { L. }\end{array}$ & 20 & 4,5 \\
\hline $\mathrm{AB}$ & Abacate & $\begin{array}{c}\text { Persea americana } \\
\text { Mill }\end{array}$ & 50 & 2 \\
\hline $\mathrm{AC}$ & Acerola & $\begin{array}{c}\text { Malpighia glabra } \\
\text { L. }\end{array}$ & 10 & 4 \\
\hline $\mathrm{J}$ & Jamelão & $\begin{array}{c}\text { Syzygium aumini } \\
\text { (Craib) Chantar. \& J. Parn. }\end{array}$ & 30 & 2,5 \\
\hline $\mathrm{L}$ & Lima & $\begin{array}{c}\text { Syzygium aumini } \\
\text { Tanaca }\end{array}$ & 10 & 20 \\
\hline \hline
\end{tabular}

H1 e H2 Cultivos de hortaliças diversas

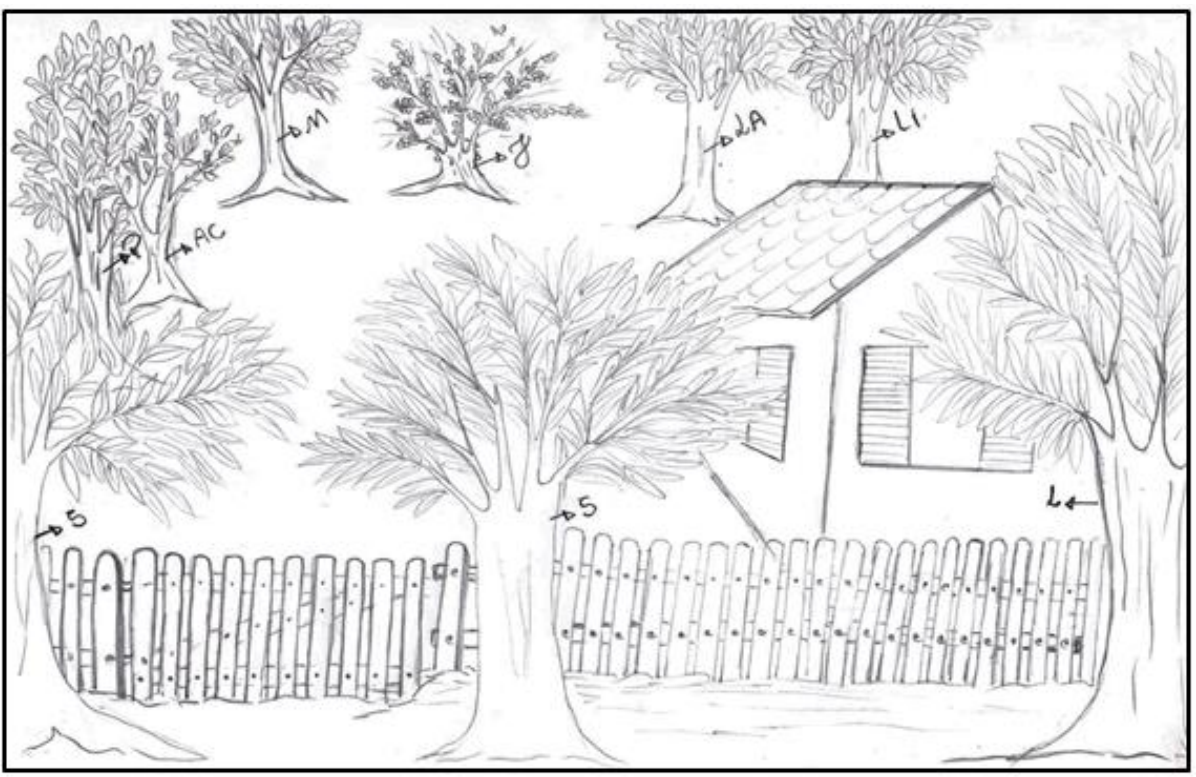

Figura 5: Croqui ${ }^{\circ}$ 02. O segundo exemplo representou 37,9\% das unidades visitadas com a casa posicionada na lateral sobre o meio do terreno, possibilitando o aproveitamento de todos os espaços que circunda a residência

Tabela 2: Informações etnobotânicas das espécies arbóreas ilustradas na figura 5.

\begin{tabular}{|c|c|c|c|c|}
\hline Identificação & Nome popular & Nome científico & Diâmetro (cm) & Altura estimada (m) \\
\hline $\mathrm{AC}$ & Ameixa & Eriobotrya japônica Rodr.et Choussy & 15 & 3 \\
\hline M & Maricota & Citrus reticulata Blanco & 20 & 4 \\
\hline $\mathrm{J}$ & Jabuticaba & Plinia trunciflora (Mart) $\mathrm{O}$. & 25 & 2,5 \\
\hline LA & Laranja & Citrus sinensis (L.) Osbeck & 25 & 4 \\
\hline LI & Limão & Citrus limonum (L.) Osbeck & 20 & 4 \\
\hline $\mathrm{L}$ & Leiteiro & Sapium glandulatum (Vell.) Pax & 30 & 4,5 \\
\hline $\mathrm{P}$ & Ponkan & Citrus reticulata Blanco & 20 & 4 \\
\hline $\mathrm{S}$ & Lima & Syzygium aumini Tanaca & 10 & 2,5 \\
\hline $\mathrm{S}$ & $\begin{array}{c}\text { Árvore-de- } \\
\text { sombra }\end{array}$ & Licania tomentosa L. & 40 & 6 \\
\hline
\end{tabular}




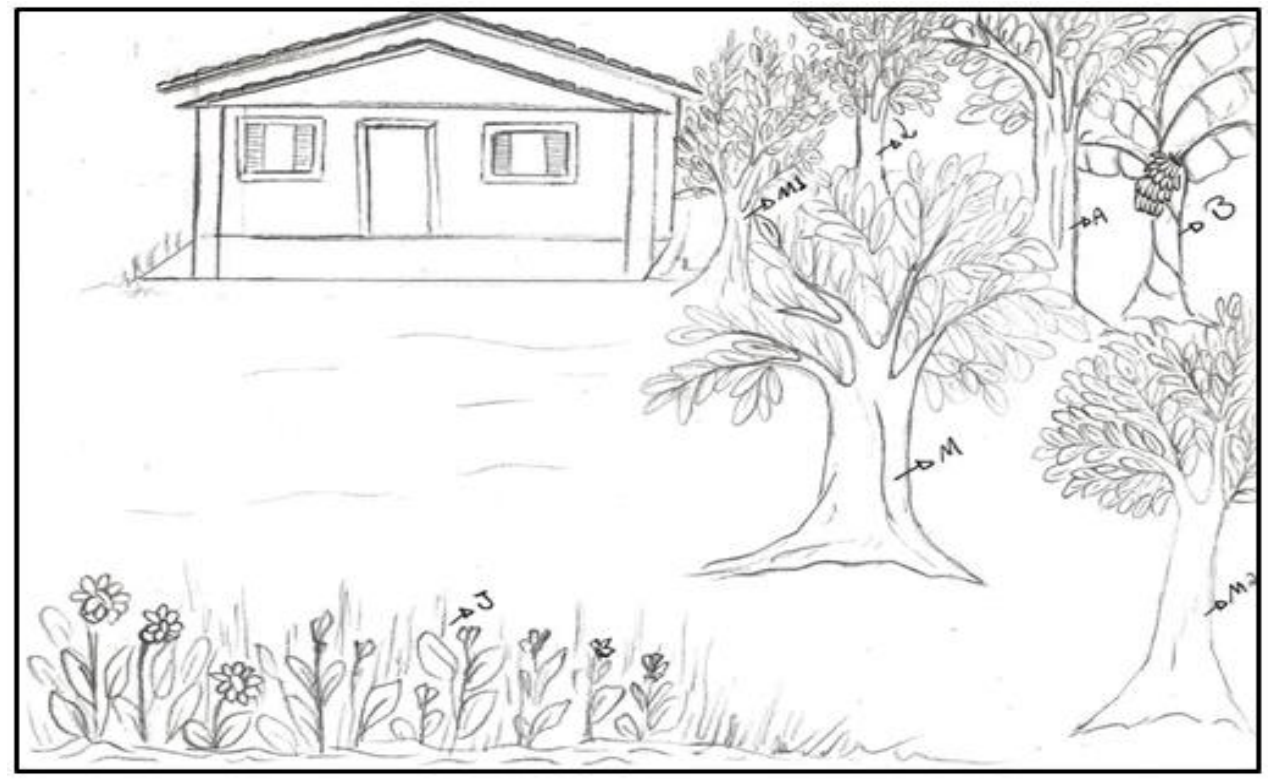

Figura 6: Croqui $\mathrm{n}^{\mathrm{o}} 3$ representou $37,9 \%$ dos quintais amostrados a casa fica situada na região central do terreno, este exemplo foi citado pelos entrevistados como uma alternativa de acessibilidade que facilita a manutenção do quintal

Tabela 3: informações etnobotânicas das espécies arbóreas ilustradas na figura 6.

\begin{tabular}{ccccc}
\hline \multirow{2}{*}{ Identificação } & Nome popular & Nome científico & \multirow{2}{*}{ Diâmetro $(\mathrm{cm})$} & Altura estimada (m) \\
\hline A & Abacate & Persea americana Mill & 50 & 5 \\
\hline B & Banana & Musa paradisíaca L. & 15 & 2 \\
\hline $\mathrm{J}$ & Jabuticaba & Plinia trunciflora (Mart) & 10 & 1,5 \\
\hline L & O. & 10 & 2,5 \\
\hline M & Manga & Citrus limettioides Tanaca & 4 \\
\hline M1 & Mexerica & Citrus reticulata Blanco & 10 & 1,5 \\
\hline M2 & Mexerica & Citrus reticulata Blanco & 20 & 3 \\
\hline
\end{tabular}

Nota referente às tabelas 3, 4 e 5: as espécies herbáceas e subarbustivas não foram ilustradas na figura, afim de não comprometer a resolução da imagem, sendo representadas apenas as espécies arbustivas e arbóreas. Porém devemos considerar a ocorrência das mesmas no contexto dos quintais.

Foi calculada ainda, a densidade de espécie por unidade doméstica e dos indivíduos considerando como referência a área total de cada unidade amostral, subtraída a área construída. De acordo com Odum (1988), esses conceitos seguem dois princípios básicos: a riqueza de espécies, baseada sobre o número total de espécies presente na área e a uniformidade, baseada na abundancia da espécie, sua dominância ou ainda, a ausência dela. Números de indivíduos registrados em cada quintal estão ilustrados na figura a seguir

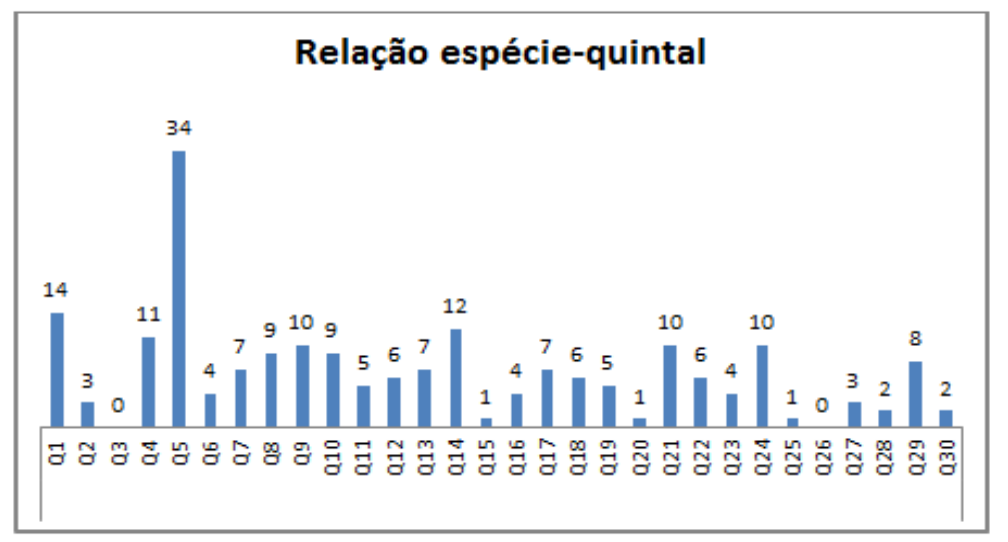

Figura 7: Números de indivíduos registrados em cada quintal 
O quintal de número cinco (05) apresentou a maior riqueza de etnoespécies representando $17 \%$ do universo estudado, sendo que $35,2 \%$ são espécies exóticas oriundas de diferentes regiões do país, com destaque maior para o estado do Rio Grande do Sul, seu local de origem.

Guarim Neto (2008 p. 88) atribui essa incidência ao fato de que essas plantas representam valores culturais diversos que os acompanham em suas rotas migratórias, deixando evidente o desejo de reproduzir ali os costumes e as tradições do seu local de origem. Essa característica também e citada por Guarim Neto e colaboradores (2008), que constataram que seus informantes traziam presente na memória e no cotidiano, informações e conhecimentos trazidos de seu local de origem, principalmente os da região sul do país, onde o universo de plantas conhecidas e com usos diferenciados daquelas tradicionalmente usados na região. Esta característica foi evidenciada no quintal de número cinco (5), onde a maioria das etnoespécies identificadas era oriunda do Rio Grande do Sul, estado de origem da informante.

De acordo com Amorozo (2002 p. 127), quem se acostuma plantar, dificilmente deixa de praticar essa atividade, mesmo depois de migrar para regiões urbanizadas. Além disso, dos informantes foi possível perceber, que apesar de residirem em área urbana, apresenta uma estreita relação com ambiente natural, fazendo dos quintais um espaço onde seja possível conciliar plantas, animais, atividades domésticas, lazer, trabalho e interação social em perfeita harmonia.

Essa relação de afetividade do proprietário em relação às plantas é evidenciada enquanto, a mesma descreve os cuidados dispensados na tentativa de obter sucesso no cultivo. Como descrito pela informante de 68 anos [...] "todos os dias, acordo cedo e venho dar bom dia e conversar com as plantas, além de água, adubo e terra boa elas gostam de atenção e carinho".

O relato acima evidencia a contribuição dos quintais na melhoria da qualidade de vida e bemestar das famílias. Conforme mencionado por Eichemberg; Amoroso, (2013), constatando em estudos sobre Agricultura Urbana em Belém, que os alimentos cultivados nos quintais tendem a ser consumidos com mais frequência, atuando de forma preventiva uma vez que os alimentos cultivados nos quintais tendem a ser mais consumidos.

Dessa forma, em regiões onde a monocultura tende a suprimir a produção de alimentos, práticas de otimização dos espaços podem representar alternativas consideráveis na produção subsistente.

Segundo Amorozo, (2002) quando se refere a "sistemas agrícolas tradicionais", normalmente está aludindo a sistemas de produção voltados principalmente para a subsistência do grupo de produtores, com utilização de insumos locais e tecnologia simples.

$\mathrm{Na}$ atual conjuntura é oportuno lembrar que a crescente demanda na produção de alimento tem sido abordada como uma das maiores preocupações de organismos e entidades como a Organização das Nações Unidas para Agricultura (FAO).

Essa diversidade pode ser observada na figura a seguir onde estão ilustrados os tipos de vegetais cultivados nos quintais estudado.

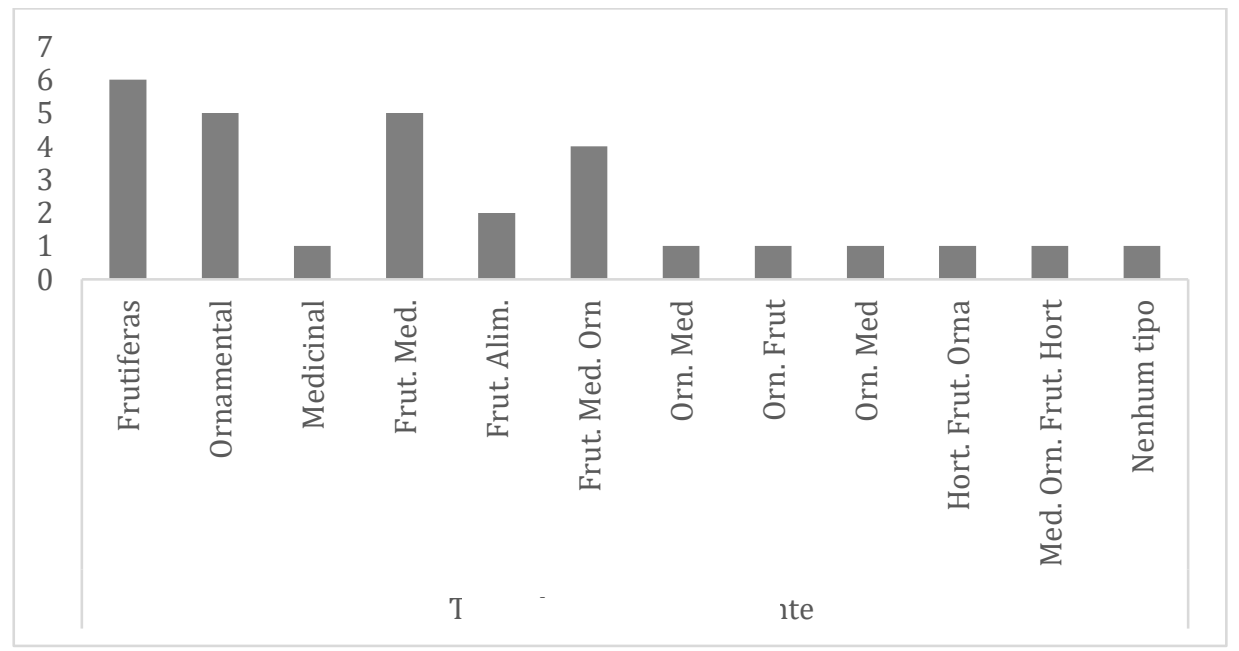

Figura 8: Tipologias de vegetais existentes nos quintais. Obs.: as informações do eixo Y correspondem ao número de vezes que foram citados. Já o eixo $\mathrm{X}$ corresponde às finalidades indicadas pelo morador. 
De modo geral podemos considerar que as plantas medicinais presentes em $62,06 \%(n=18)$ dos quintais visitados são utilizadas como uma alternativa no tratamento de doenças e sintomas agudos, conforme mencionados por G. S. 68 anos:

[...] não podemos depender dos médicos pra tudo. Quando não me sinto bem, faço um chá e logo passa, minha mãe me ensinou muitos remédios, más com o passar do tempo fui perdendo as mudas e hoje só restou essas. [...] além de mim, minhas vizinhas também buscam folhas aqui, então por mais que a gente cuida elas não estão muito bem.

Declarações como esta deixam evidente a importância dos quintais na manutenção das relações de vizinhanças e na transmissão de conhecimentos relacionados ao uso e do compartilhamento dos recursos vegetais com propriedades terapêuticas ao longo de gerações. Amoroso (1981) citado por Benini e Godoy (2016 p. 352), chama atenção para o cultivo de plantas nos quintais que são utilizadas no tratamento de doenças. Acrescenta ainda que quando utilizadas de maneira adequada, as plantas apresentam efeito terapêutico e os efeitos colaterais são amenizados.

Sobre as plantas medicinais, os resultados deixaram evidentes o que o uso deste recurso é mais acentuado em indivíduos mais velhos, em detrimento das gerações mais jovem, mesmo que estes tenham tido acesso a escolaridade. Brasileiro e colaborados (2008) constataram que há uma perda significativa na transmissão desses conhecimentos. Medeiros e colaboradores (2004) atribuem este fato aos meios modernos de comunicação que causam a perda da transmissão oral de conhecimentos sobre os recursos vegetais.

Ainda sobre as plantas medicinais é interessante observar que as buscas pelo conhecimento das propriedades terapêuticas se intensificam na medida em que os jovens ao se tornarem pais, buscam orientações de pessoas próximas como mãe e avó sobre como fazer uso da mesma, com a chegada do novo membro do núcleo familiar.

Algumas dessas espécies além de medicinal apresentam outras finalidades como no caso das plantas consideradas "mágicas" pelos entrevistados, essas são cultivadas com intuito de atrair sorte e proteção aos moradores, espantar mal olhado, benzimentos entre outros.

As principais plantas identificadas para essas finalidades são Guiné (Petiveria alliacea L.), Espada de São Jorge (Sansevieria trifasciata Prain), Arruda (Ruta graveolens L.), Jurema da sorte (Polysci asguilfoylei (W. Bull) L. H. Bailey) e a Rosa (Rosa sp.), esses vegetais encontram-se inseridos junto ao jardim que de acordo com G.S de 68 anos:

[...] elas ficam ai, meio escondidas no meio das outras, a sim eles protegem a casa, os moradores e quase ninguém percebe, as pessoas pensam que é flor. Revela informante e, complementa dizendo, [...] elas são tão sensíveis que quando alguém da casa fica doente elas ficam também ficam. Agora mesmo fiquei internada vários dias, e como você pode ver as folhas estão murchas e amarelas, más logo ela se recupera, assim como eu.

Essas crenças e valores estão encontram-se inseridos de modo intrínseco na população, neste contexto os quintais representam muito mais do que uma mera porção de terra, mas algo, do qual eles se veem como parte integrante.

Dessa forma, compreender profundamente essas questões implica em colocar-se em um sistema social determinado no tempo e no espaço, no qual estão transcritos valores, símbolos e a história de vida de cada um.

\section{CONSIDERAÇÕES FINAIS}

Considerando os resultados apresentados percebe-se que quintais urbanos do município de Ponta Porã-MS, representam grande diversificação em relação ao cultivo e uso das espécies catalogadas no estudo, principalmente as de cunho alimentício, medicinal, ornamental e místico. Sendo que em ambos os casos esses vegetais foram citados finalidades distintas, sendo que $93 \%$ dos quintais visitados apresentaram pelos menos uma das finalidades descritas acima.

Vale ressaltar a composição florísticas que constitui a comunidade vegetal dos quintais estudados compreende desde pequenas briófitas até as frondosas angiospermas como a abacateiro (Persea americana Mill.) e as mangueiras (Mangifera indica L.) que além de fornecerem os frutos utilizados na 
alimentação do núcleo familiar, ainda é possível apreciar suas sombras, fornecendo aos moradores abrigo para adultos e crianças com temperaturas amenas nos dias quentes de verão.

Tal como fora explanado na metodologia, este trabalho buscou identificar e caracterizar a estrutura etnobotânicas dos quintais urbano de Ponta Porã-MS, e assim compreender as relações estabelecidas entre a sociedade e os recursos vegetais. No entanto, essa experiência contribui também, na compreensão dos pesquisadores ao concluir seu trabalho pode compreender que os estudos etnocientíficos, assim como a análises qualitativas como forma de promover uma ciência que esteja aberta e dialógica exigem do pesquisador uma postura ainda mais rigorosa, se comparadas a análise de informações puramente quantitativas para não se correr o risco de abandonar o rigor cientifico, mas sim, uma forma de se deixar fluir os conhecimentos produzidos pelas comunidades locais em contribuição ao meio científico. No entanto, o cumprimento de todos esses requisitos forneceu subsídios fundamentais para a caracterização dos resultados obtidos.

Com tudo é importante salientar que os estudos nessa área estão longe se esgotar, pois além do Brasil ser considerado uns dos países mais ricos em biodiversidade no mundo, é detentor uma grande riqueza cultural e étnica que tem como resultado um acúmulo de conhecimentos e tecnologias tradicionais, dentre ele destaca-se um vasto acervo de conhecimentos sobre uso e manejo dos vegetais, que são repassados de geração em geração. Tal como fora evidenciado neste pequeno ensaio.

Diante disso, podemos considerar que os quintais fronteiriços representam um importante refúgio de espécies vegetais com potencial amplamente explorado pela população, que através de seus conhecimentos e práticas tradicionais de manejo, fazem o uso de forma harmônica, promovendo a manutenção e conservação das espécies.

\section{REFERÊNCIAS}

ALBUQUERQUE, U. P. Introdução a etnobotânica. Editora Interciência. $2^{\circ}$ ed. 93p. 2005.

AMOROZO, M. C. M. Os quintais: funções, importância e futuro. GUARIM NETO, G.; CARNIELLO, M.

A. Quintais mato-grossenses: espaços de conservação e reprodução do saberes. Cáceres: Editora Unemat, 2008. AMOROZO, M. C. M. Uso e diversidade de plantas medicinais em Santo Antonio do Leverger, MT, Brasil. Acta Botanica Brasílica, v.16, n.2, p.189-203, 2002.

AMOROZO, M. C. Um sistema de agricultura camponesa em Santo Antônio do Levenger. Mato Grosso, Brasil. 1996. 232f. Tese (Doutorado em Antropologia). São Paulo: Universidade de São Paulo, 1996.

BARDIN, L. 1997. Análise de conteúdo. Edição revista actualizada. p 282.

BARUFFI, H. Metodologia da pesquisa: manual para elaboração da monografia. 3 ed. Dourados: Hbedit, 2002. $181 \mathrm{p}$

BEGOSSI, A. Ecologia Humana: Um Enfoque Das Relações Homem-Ambiente. Interciencia. n. 18: p.121132, 1993. Disponível em: 〈http://www.interciencia.org.ve>. Acesso em: 12 Nov. 2016.

BENINI, S. M.; GODOY, J. A. R. S. Estudos Urbanos: uma abordagem interdisciplinar da cidade contemporânea. 2. Ed. - Tupã: ANAP, 2016.

BRITO, A. R. M. S.; BRITO, A. A. S. Medicinal plants research in Brazil: data from regional and national meetings. In: BALICK, M. J.; ELISABETSKY, E.;

CARNIELLO, M. A.; SILVA, R. S.; CRUZ, M. A. B.; GUARIM NETO, G. Quintais urbanos de Mirassol D’Oeste-MT, Brasil: uma abordagem etnobotânica. Acta Amazônica. vol.40 n. 3 Manaus set. 2010.

FREITAS, A. V. L. COELHO, M. F. B.; MAIA, S. S. S.; AZEVEDO, R. A. B. Plantas medicinais: um estudo etnobotânico nos quintais do Sítio Cruz, São Miguel, Rio Grande do Norte, Brasil. Revista Brasileira de Biociências, v.10, n.1, p. 48-59, 2012.

GUEDES-BRUNI, R. J. Inventário Florístico In: Manual Metodológico para estudos botânicos na Mata Atlântica. 2002. p. 121. Disponível em:<https://pt.scribd.com/doc/175199534/Manual-Metodologico-ParaEstudos-Botanicos>. Acesso em: 02 dez. 2016.

GUARIM NETO, G. Refletindo sobre ambiente e cultura - a etnobiologia, a etnoecologia, a etnobotânica: o saber tradicional instalado e mantido. Anais do III Fórum de Educação e Diversidade: Educação em contexto intelectual. Universidade do Estado de Mato Grosso. Tangará da Serra, MT, jun. 2008. Disponível em: <http://need.unemat.br/3_forum/artigos.html >. Acesso em: 12 Nov. 2016.

GUARIM NETO, G. Refletindo sobre ambiente e cultura. A etnobiologia, a etnoecologia e a etnobotânica: O saber tradicional instalado e mantido. Disponívelem: <http://docplayer.com.br/15121043-Refletindo-sobreambiente-e-cultura-a-etnobiologia-a-etnoecologia-e-a-etnobotanica-o-saber-tradicional-instalado-emantido.html>. Acesso em: 09 Nov. 2016.

IBGE, Manual técnico da vegetação brasileira. Rio de Janeiro: IBGE, 2002. 271 p. $2^{\circ}$ ed. (Manuais técnicos de Geociências, 1). Disponível em:〈http://biblioteca.ibge.gov.br/visualizacao/livros/liv63011.pdf $>$. Acesso em: 01 Nov. 2016. 
IBGE. Instituto Brasileiro de Geografia e Estatística. Cidades: Mato Grosso do Sul - Ponta Porã. Disponível em: <http://imguol.com/2012/10/04/mapa-de-ponta-pora-ms-1349402942335_300x300.jpg>. Acesso em: 27 nov. 2016.

KORMONDY, Edward J. BROWN, Daniel E. Ecologia Humana. São Paulo. Atheneu, 2002. 503 p.

MAIA, S. G. C. Aspectos do mecanismo de compensação da reserva legal em unidades de conservação no estado de Mato Grosso: Parque Estadual Encontro das Águas, pantanal mato-grossense. $2011.177 \mathrm{f}$. Dissertação (Mestrado). UFMT. Cuiabá, MT, 2011.

MILLAT E MUSTAFA, M. An approach toward analysis of home gardens. In: RASTOGI, A.; GODBOLE, A.; SHENGJI, P. (Eds.) Applied Ethnobotany in Natural Resource Management. Traditional Home Gardens. International Center for Integrated Mountain Development, Nepal, 1998. pp. 39-48.

MOURA, C. L.; ANDRADE, L. H. C. Etnobotânica em quintais urbanos nordestinos: um estudo no bairro da Muribeca, Jaboatão dos Guararapes, PE. Revista Brasileira de Biociências, v.5, n.1, p. 219-221. 2007. Disponível em: 〈file:///C:/Users/User/Downloads/213-1948-2-PB\%20(1).pdf>. Acesso em: 24 Nov. 2016.

NAIR, P. K. R. An introduction to agroforestry. Kluwer Academic Publishers, 1993. Disponível em: <http://www.worldagroforestry.org/Units/Library/Books/PDFs/32 An introduction to agroforestry.pdf?n=161 $>$. Acesso em 10 Nov. 2016.

NODA, S; CHUTINAN, A; IMADA, M. Trapping and emission of photons by a single defect in a photonic bandgap structure. Nature, v. 407, n. 6804, p. 608-610, 2000.

PASA, M. C. Um olhar Etnobotânico sobre as comunidades do Bambá. Cuiabá: Entrelinhas: EdUFMT, 2007.

POSEY, D. A. Etnobiologia: Teoria e Práticas. Suma Etnobiológica Brasileira. Petrópolis, vol. 1 (Etnobiologia), 1987.

RAVEN, P.; EVERT, R. F.; EICHHORN, S. E. Biologia Vegetal. 7 ed. Rio de Janeiro: Guanabara Koogan, 2011.

RONDON NETO, R. M. R.;BYCZKOVSKI, Á; WINNICKI, J. A,; SIMÃO, M. M.;

SILVA, V. A.; ALMEIDA, A. L. S. Etnobiologia e atnoecologia. Pessoas e natureza na América Latina. Recife NUPEEA, 2010.

VIEIRA, T. A.; ROSA,L. S.; SANTOS. M. M. L. S. Agrobiodiversidade de quintais agroflorestais no município de Bonito, Estado do Paraná. Revista de Ciências Agrárias. v. 55, p 159-166, 2012. Disponível em: <http://doi.editoracubo.com.br/10.4322/rca.2012.054> Acesso em: 23 Out. 2016. 